\title{
Distribution Characteristics of Air Anions in Beidaihe in Different Ecological Environments
}

\author{
Xiakun Zhang', Jianxin $\mathrm{Cao}^{2}$, Shuyu Zhang3,4* \\ ${ }^{1}$ National Meteorological Center, Beijing, China \\ ${ }^{2}$ Qinhuangdao City Meteorological Bureau, Qinhuangdao, China \\ ${ }^{3}$ Key Laboratory of Meteorology and Ecological Environment of Hebei Province, Shijiazhuang, China \\ ${ }^{4}$ Hebei Provincial Meteorological Bureau, Shijiazhuang, China \\ Email: zxk668@126.com,caojianxinq@sina.com, *zhangsy@cma.gov.cn
}

How to cite this paper: Zhang, X.K., Cao, J.X. and Zhang, S.Y. (2018) Distribution Characteristics of Air Anions in Beidaihe in Different Ecological Environments. Journal of Geoscience and Environment Protection, 6, 133-150.

https://doi.org/10.4236/gep.2018.65012

Received: November 20, 2017

Accepted: May 22, 2018

Published: May 25, 2018

Copyright $\odot 2018$ by authors and Scientific Research Publishing Inc. This work is licensed under the Creative Commons Attribution International License (CC BY 4.0).

http://creativecommons.org/licenses/by/4.0/ Open Access

\begin{abstract}
Qinhuangdao is a provincial municipality under the jurisdiction of Hebei Province and a coastal city in China. Beidaihe is a district under the jurisdiction of Qinhuangdao and is a famous seaside scenic area. Alliance Peak, located in Beidaihe seashore scenic West. Jinshan mouth is the peak of the Union Peak, located in the easternmost Beidaihe waterfront. In this paper, we use the observed data of air negative ions in the Beidaihe, Qinhuangdao, Jinshanzui and Lianfeng Mountains for seven years to study the distribution characteristics of negative air ions in different ecological environments through meteorological observation. Research shows that the annual mean of air anion concentration fluctuates less. The annual mean is 1730 ind $\cdot \mathrm{cm}^{-3}$, and the difference between the highest and lowest concentrations is 535 ind $\cdot \mathrm{cm}^{-3}$. The average air anion concentration was the highest in August at 7785 ind $\cdot \mathrm{cm}^{-3}$ and the lowest in January at $365 \mathrm{ind} \cdot \mathrm{cm}^{-3}$. Negative air ions have obvious spatial characteristics, and negative ion concentrations of the sea and forest air are significantly high. The average annual mean of the sea is $3902 \mathrm{ind} \cdot \mathrm{cm}^{-3}$, and that of the forest is $5403 \mathrm{ind} \cdot \mathrm{cm}^{-3}$. The concentration of air anion changes daily, and daytime concentration is significantly lower than nighttime concentration. The highest peak appears at night or in the morning, while the lowest value appears between noon and afternoon. Inter-annual features and concentration of negative air ions, as well as annual rain days, total rainfall, thunderstorm days, and average relative humidity, are negatively related to the annual average temperature and sunshine hours. However, in the average concentration of negative air ions, the average correlation test of meteorological elements was insignificant. The air anion concentration is negatively correlated with the PM2.5 concentration of fine particulate matter. The concentrations of nitrogen dioxide, sulfur dioxide, and carbon monoxide in the fine particulate matter are negatively correlated with the ozone concentration,
\end{abstract}


which is positively correlated with ozone concentration and is tested by significance. Atmospheric discharge (thunderstorm) can produce a considerable amount of air anion. Air negative ions are an important indicator of air quality, which is of great significance to the living environment. The distribution of negative ions in the study space and its influencing factors in order to provide a basis for air quality assessment in the region and provide references for the long-term research on air anion in different urban areas.

\section{Keywords}

Ecological Environment, Negative Air Ion, Distribution Characteristics, Correlation Coefficient

\section{Introduction}

Negative air ions are negatively charged gas ions in the air. The "capture" capability of oxygen is stronger than other air molecules, and preferential access to free electrons form negative air ions. Thus, negative air ions are mainly composed of negative oxygen ions. Negative air ions were first discovered by German scientists Elster and Gertel in 1889 and Asamas et al. in 1902; they affirmed the biological significance of the presence of air ions [1] [2], marking the official start of studies on negative air ions. In 1903, A. B. C. Okosob, a Russian scholar, first published an academic paper on the treatment of diseases with air anions [3] [4]. In the 1980s, the biological effects of air ions on biological organisms and neurological and immune systems, as well as the measurements of environmental air ion, were studied. Shalnov highlighted that negative air ionization enhances the immune function of the body [5] [6]. In the 1990s, studies gradually shifted to applications, such as the distribution and evolution of air and negative ions in sanatorium and nursing homes, as well as the provision of rehabilitation services [7]. Zhou et al. [8] reported that air anion in recuperation sites is positively correlated with plant density and highly sensitive to the ecological environment. Since entering the 21st century, the development of air anion resources as an important aspect of ecological tourism depth development [9] for different ecological functions of negative air ions and meteorological elements has been studied. Moreover, relative humidity and light intensity of air have been reported as the main factors that influence the concentration of negative air ions [10]. A light city climate can be achieved by planting trees and plants and building artificial fountains; simply planting grass will not significantly increase air anions [11] [12]. Air pollution in living areas with high population density and little vegetation is significantly higher than areas with more dispersed plants. Air anion concentration represents the degree of air freshness in an area [13]. In recent years, plant communities have gradually increased along with the urban green space research effects of negative air ions. Liu [14] reported that the leaf area index of plant communities, such as LAN, and community microclimate, 
have an important influence on the amount of negative air ions; negative air ions and air quality play a key role in the ascension of vegetation of urban functional areas [14] [15]. Different greening configuration modes of green land concentration of negative air ions also show obvious difference in concentration and air quality to the size of the order are all stand of grass type $>>$ Joe bringing type $>$ grassland $>$ bare land [16]. Meanwhile, increasing studies on meteorological factors, such as solar radiation, wind, rain, air humidity, and fog, have been conducted. Chang [17] et al. reported that anion increases when the sunshine is clear, the concentration of negative air ions is low, and the weather is mild; negative air ions and humidity are different in each season. In a typical urban residential area, the concentration of negative air ions and temperature, vapor pressure, and wind speed are significantly positively related; UV [18] is positively correlated with relative humidity [19], and the concentrations of negative air ions and PM2.5 are significantly negatively correlated [20]. Overall, the relationship between negative air ions and the key influencing factors and their interactions are studied. Despite the long and extensive research history on negative air ions, several issues still exist as follows: "defects and bottlenecks" with data problems; the "scale" and "data link" observation of negative air ions are still in a local state; short data chain; and small volume of data; these issues cannot reflect the air anion "macro distribution", and the status of the air anion cannot be obtained. This paper adopts the same city with different biomes, seven consecutive years of monitoring data, a long time span, and the data chain length to study the distribution characteristics of different ecological environments.

\section{Research Area Overview and Research Methods}

\subsection{Overview of the Research Area}

Qinhuangdao Beidaihe, which is in the northwest of Bohai bay, is a famous tourist resort in China. This area has a warm temperate zone and a semi-humid, monsoon continental climate and is affected by sea breeze all year round. The annual average temperature is $10.2^{\circ} \mathrm{C}$, the annual rainfall days is 67 , the annual rainfall is $676.7 \mathrm{~mm}$, the annual sunshine is 2996 hours (average sunshine percentage of $63 \%$ ), and the annual average relative humidity is $69.3 \%$. In summer, the average temperature is $22.9^{\circ} \mathrm{C}$. The average temperature in July is $24.6^{\circ} \mathrm{C}$, which is $30^{\circ} \mathrm{C}$ higher than the temperature throughout the year days to 18.7 days and higher than 35 live for 1.1 days statistical period (1986-2015).

In Bedaihe, the meteorological observation, Jinshanzui, and Lianfengshan are selected for the air anion observation experiment. Figure 1 illustrates the position of Beidaihe, the meteorological observation is located at $39^{\circ} 51^{\prime} 11.23^{\prime \prime} \mathrm{N}$, $119^{\circ} 30^{\prime} 40.33^{\prime \prime} \mathrm{E}\left(2.4 \mathrm{~m}\right.$ above sea level), the location of Jinshanzui is at $39^{\circ} 49^{\prime}$ $10.82^{\prime \prime} \mathrm{N}, 119^{\circ} 31^{\prime} 45.71^{\prime} \mathrm{E}$ (1.2 $\mathrm{m}$ above sea level), and the location of Lianfengshan is at $39^{\circ} 49^{\prime} 27.33^{\prime \prime} \mathrm{N}, 119^{\circ} 27^{\prime} 12.93^{\prime \prime} \mathrm{E}$ (153 m above sea level). The meteorological observation distance is $4.44 \mathrm{~km}$ from Jinshanzui, which is $5.51 \mathrm{~km}$ from Lianfengshan. The distance of Jinshanzui from Lianfengshan is $6.30 \mathrm{~km}$. 


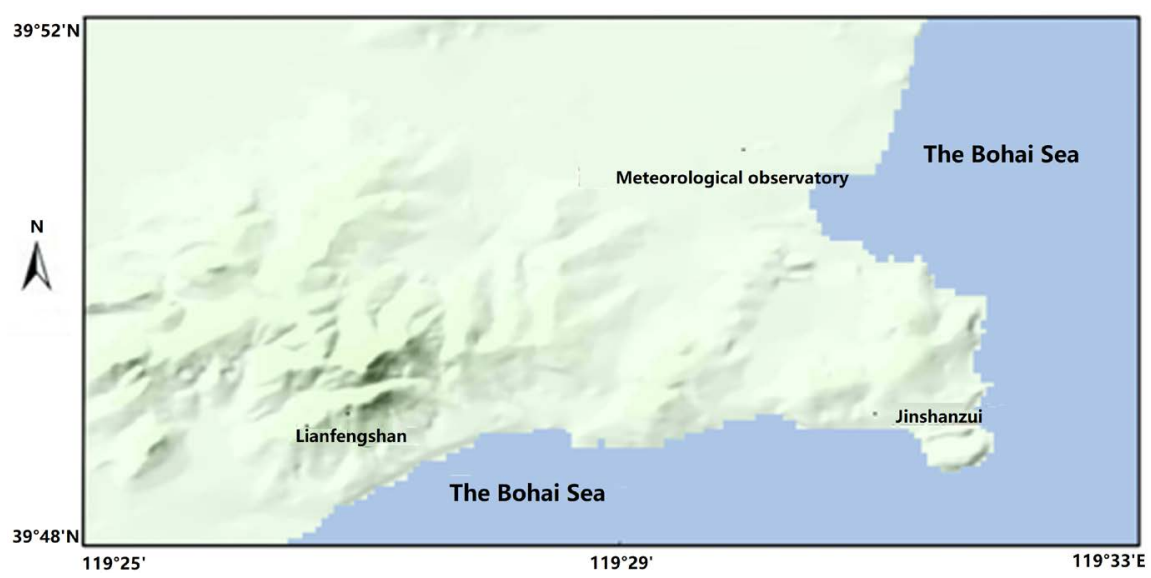

Figure 1. Location of automatic meteorological observatory for obtaining air anion data.

The underlying surface of the three observation sites are as follows. The meteorological observation site comprises beaches and bushes. The 577.4 ha beach area is composed of beaches, lagoons, and rivers and mainly planted with poplar (Populus 1.), willow (Salix babylonica 1.), and black locust (Robinia pseudoacacia Linn.) trees. The 6603 ha forest area of Lianfengshan is mainly planted with $P i$ nus tabulaeformis (Pinus tabulaeformis Carr.), pine (Pinus thunbergii Parlatore), masson pine (Pinus massoniana Lamb.), and white birch (Betula platyphylla Suk.), with a spruce (Picea asperata Mast.), five huwg (Acer elegantulum Fang et p. 1. Chiu), purple Ye Li (Prunus cerasifera CV. Pissardii), smoke tree (Cotinus coggygria Scop.), and other colored tree species. The ground is often seen in the wild (Setaria viridis (Linn.) Beauv.). Jinshanzui is surrounded by sea, and its northern area is planted with Pinus tabulaeformis Carr. and Pinus massoniana Lamb.

\subsection{Research Methods}

\subsubsection{Experimental Data and Instruments}

In May of 2006, the "negative air ion" observation test was conducted in Beidaihe, Qinhuangdao. The basic data includes the average hourly rate of air anion concentration, which is the continuous data value for 2009-2015. The meteorological observation, Jinshanzui, and Lianfengshan each have 54,655 valid data.

The monitoring instrument used was WIMD, which is an atmospheric air anionic automatic instrument developed by Beijing Wanda Technology Co., Ltd. The air anion migration rate of the instrument is divided into two parts: 1) transfer rate $\mathrm{k}=1.0$, where the migration rate is greater than 1.0; and 2) transfer rate $\mathrm{k}=0.4$, where the removal rate is greater than 0.4 negative air ions. In this paper, the data of negative air ions used for $\mathrm{k}=1.0$ are characterized by very small anions, long retention time, and strong biological activity. Negative air ions are also breathed in very easily into the alveolar and affect the cerebral circulation in the blood. 


\subsubsection{Data Processing}

Excel was used to create the air anionic concentration curve. The statistical observation data, calculation of standard deviation, analysis of the correlation among air anionic concentration, meteorological elements, and atmospheric pollutants, and the significance test of correlation coefficients are discussed.

\section{Space-Time Distribution of Air Anion}

\subsection{Time Distribution of Negative Air Ions}

\subsubsection{Annual Change of Air Anion Concentration}

Figure 2 shows the average of air negative ion concentration from 2009 to 2015. The average annual mean of air anionic concentration is $1730 \mathrm{ind} \cdot \mathrm{cm}^{-3}$, which is the highest in 1927 and 1.1 times the annual mean. In 2014, the lowest was 1392 ind $\cdot \mathrm{cm}^{-3}$, which was 0.81 times the mean. The average difference between the highest and lowest concentrations is 535, with a maximum of 1.38 times the minimum. The highest average belongs to 2012 because its rainy days (75 days), precipitation $(1234 \mathrm{~mm})$, and number of lightnings (28) were significantly greater than the precipitation days (60 days), precipitation $(352 \mathrm{~mm}$ ), and number of lightnings (20 times) in 2014. Precipitation can produce a considerable amount of air anion [21], and abundant rainfall is beneficial to local vegetation growth and increasing biological discharge, surface water area, and air humidity.

According to the average of the four seasons, the concentrations of air anion in seven years are as follows: $4112 \mathrm{ind} \cdot \mathrm{cm}^{-3}$ in summer, $1821 \mathrm{ind} \cdot \mathrm{cm}^{-3}$ in autumn, 377 ind $\cdot \mathrm{cm}^{-3}$ in winter, and 611 indc. $\mathrm{m}^{-3}$ in spring. The concentrations in summer and autumn are significantly higher than those in winter and spring. The distribution of negative air ions has a direct relationship with the local environment and climate because the vegetation period of dead leaves in the Beidaihe region is in the middle of late November and April of next year. In addition,

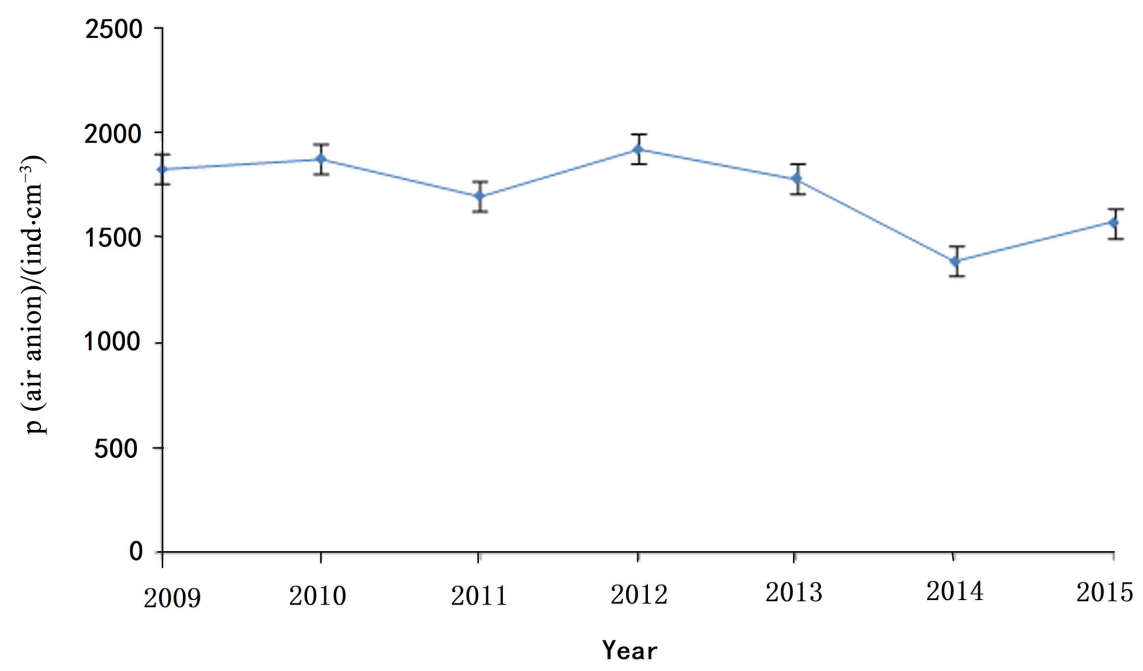

Figure 2. Change on annual average mass concentration of anion in seven years. 
the meteorological observation of the surrounding vegetation with tall deciduous trees is given priority. Leaves stage of plant photosynthesis significantly decreased and the winter air moisture content is low. The discharge capacity and free electrons combined with oxygen capability is limited, thereby causing the lower concentration of negative air ions in fall than in the winter and spring. Summer and fall in Beidaihe are influenced by wind, and its winter is influenced by land breeze. The wind is onshore wind, and the sea wind forms large waves that are conducive to the generation of significant quantities of negative air ions. Therefore, the freshness of fall air and the characteristics are obvious, especially in the coastline. The forest has low temperature, high humidity, and vegetation growth, and the release of air anion is high [22]. Meanwhile, summer and autumn are in the middle of the growth of Beidaihe plants.

Define abbreviations and acronyms the first time they are used in the text, even after they have been defined in the abstract. Abbreviations such as IEEE, SI, MKS, CGS, sc, dc, and rms do not have to be defined. Do not use abbreviations in the title or heads unless they are unavoidable.

\subsubsection{Monthly Change in Air Anion Concentration}

Figure 3 shows the average line chart of the air anion concentration in seven years (2009-2015). In 12 months, the average concentration was highest in August at 7785 ind $\cdot \mathrm{cm}^{-3}$ and lowest in January at 365 ind $\cdot \mathrm{cm}^{-3}$. The 2010 study of Dalian city by Cong Qing [23] presented an opposite conclusion, that is, the negative oxygen ion concentration in winter was high and that of summer was low (data from March, 2008 to February, 2009). The average monthly concentrations in winter and spring are below 500 ind $\cdot \mathrm{cm}^{-3}$, except in May, which is 992 ind $\cdot \mathrm{cm}^{-3}$. The air anion concentration in the figure is significantly higher in August than in the other months, which is 2.8 times higher than that of the month of September. This phenomenon is associated with favorable climate and environment background in August because the precipitation and rainfall in Beidaihe in August hold the extreme values of the entire year. Moreover, the atmospheric environment is best in August, as shown in Figure 4. In August, the number of leaves on the ground surface is the highest in the entire year. Apart from the highest concentration of air anion in August, air anion concentration is significantly higher in May to October than in other months. In late November to mid-April of the following year, during the vegetation period of withered leaves in Beidaihe region, in which the vegetation around the station is mainly tall deciduous trees, plant photosynthesis significantly decreases, the air humidity of withered leaves becomes small, and the rainfall, biological discharge capability, and the capability of free electrons to combine with oxygen are restricted. This phenomenon can be attributed to the significant reduction of negative air ion concentrations in the winter and spring.

\subsubsection{Twenty-Four-Hour Change of Seasons of Air Anion Concentration}

Figure 5 shows the various air anion concentrations in the four seasons of Beidaihe, 


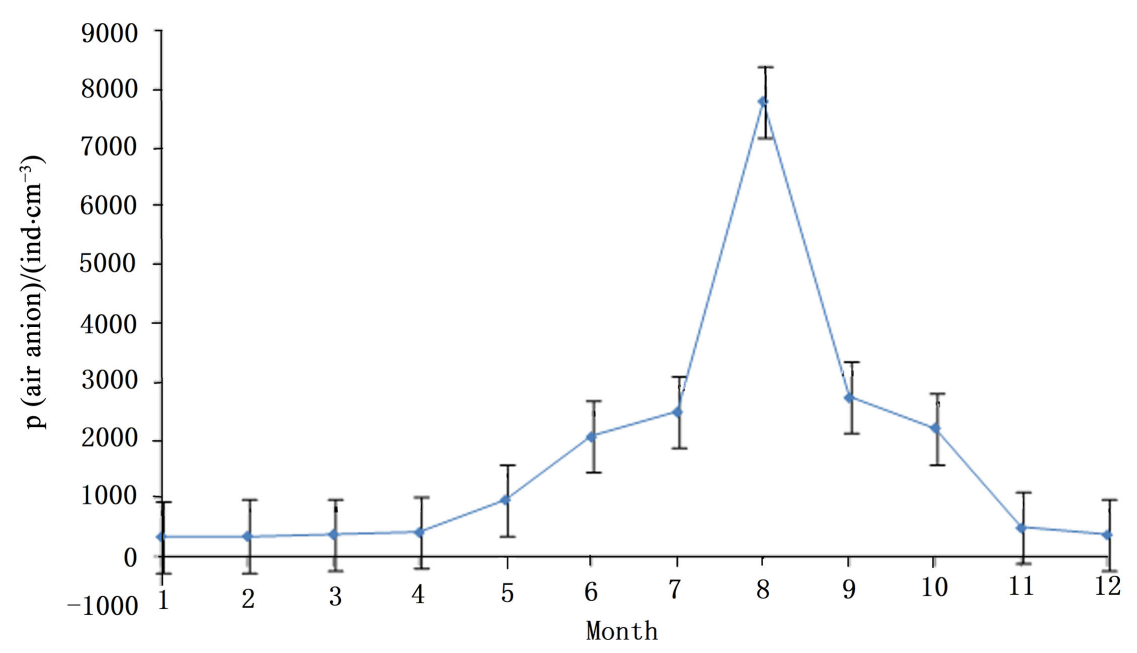

Figure 3. Line chart on the monthly average mass concentration of the air anion in Beidaihe.

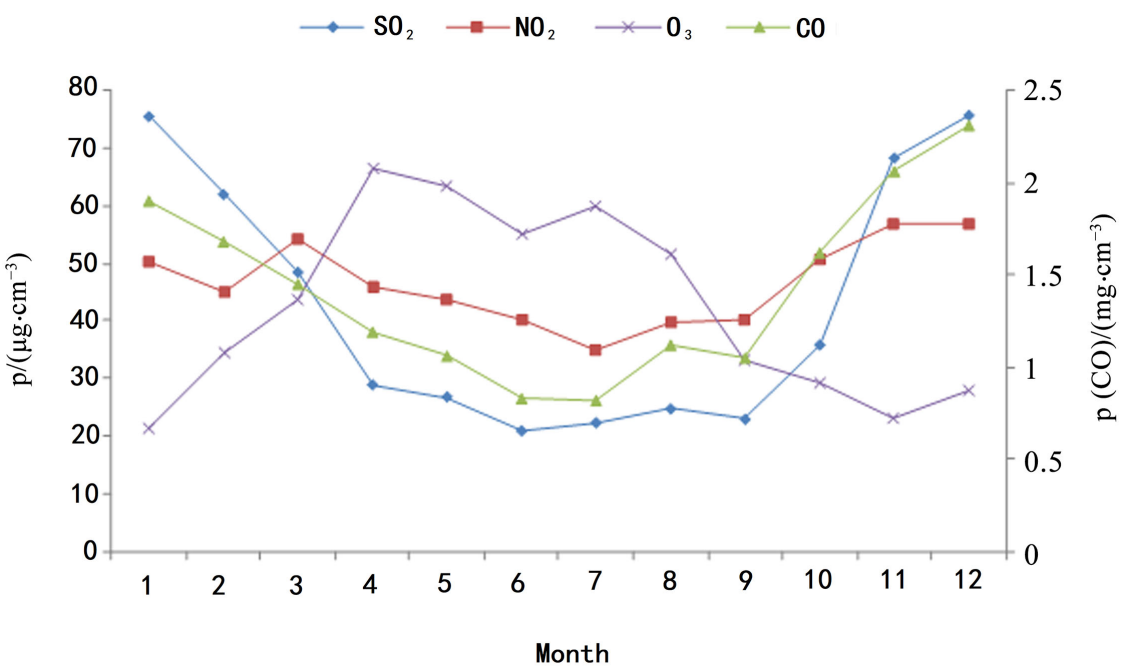

Figure 4. Line chart on the monthly average mass concentration of the main air pollutants (carbon monoxide units is $\mathrm{mg} \cdot \mathrm{m}^{-3}$ and the other is $\mu \mathrm{g} \cdot \mathrm{m}^{-3}$ ).

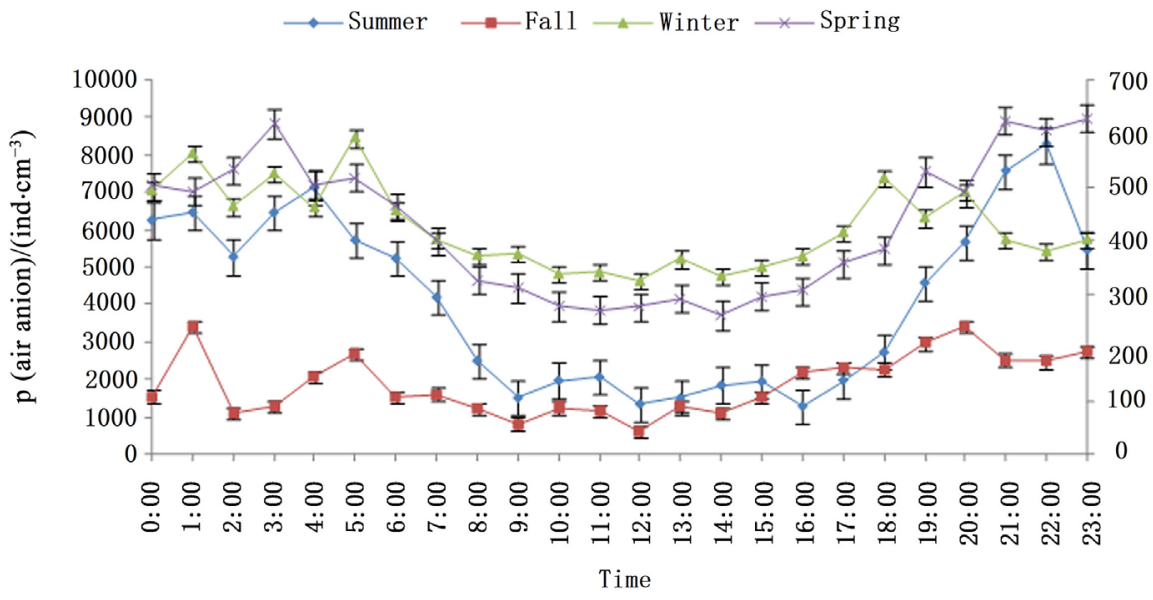

Figure 5. Line chart on the change of anion mass concentration in 24 hours at all seasons. 
"spring summer and autumn winter". For example, the change of spring 24 hours means that between 2009 and 2015, spring 00:00, 01:00, and so on. At 23:00, the arithmetic mean of air anion concentration. In Figure 5, the peak value of air anion concentration at night is at 22:00 and is $8265 \mathrm{ind} \cdot \mathrm{cm}^{-3}$, and the lowest value is at 16:00 and is 1293 ions. The maximum value in autumn is at 20:00 and is $3412 \mathrm{ind} \cdot \mathrm{cm}^{-3}$, and the lowest value is $628 \mathrm{ind} \cdot \mathrm{cm}^{-3}$ at 12:00. The maximum winter concentration at 05:00 is $591 \mathrm{ind} \cdot \mathrm{cm}^{-3}$ and the lowest value is $324 \mathrm{indc} \cdot \mathrm{m}^{-3}$ at 12:00. The maximum spring concentration is $628 \mathrm{ind} \cdot \mathrm{cm}^{-3}$ at 23:00, and the lowest value is 260 ind $\cdot \mathrm{cm}^{-3}$ at 14:00. The air anion concentration is low at 8:00-18:00, in which night concentration is higher than that at daytime. The concentration of air anion in autumn is less than that at night and its 24 hours fluctuation. In winter, the air anion concentration is relatively high at 18:00 to 20:00 and low at other times. The concentration of air anion in spring is obvious. In Figure 5, the air anion concentration in a day changes in 24 hours, and the difference between the four seasons is obvious.

\subsubsection{Twenty-Four-Hour Change of Air Anion Concentration during Tourist Season}

June, July and August, three months is Beidaihe peak travel season, which is characterized by summer and leisure convalescence. During this period, air anion is most seasonal. The average concentrations in June, July, and August are 2064 ind $\cdot \mathrm{cm}^{-3}, 2488$ ind $\cdot \mathrm{cm}^{-3}$, and 7786 ind $\cdot \mathrm{cm}^{-3}$, respectively. In Figure 6, the concentration of air anion in July is slightly higher than that in June. The concentration of air anion in August is 3.1 times that in July. During summer, the air anion concentration is low at 9:00-17:00, and the difference is particularly pronounced in August. The maximum air anionic concentration usually occurs at 22:00 and 6:00. In June, the average minimum concentration is at 15:00 at 731 ind $\cdot \mathrm{cm}^{-3}$. At 17:00 in July, the average minimum concentration is $1011 \mathrm{ind} \cdot \mathrm{cm}^{-3}$. At 13:00 in August, the average minimum concentration is 1497 ind $\mathrm{cm}^{-3}$. During summer in Jinshanzui (June, July, and August), the average concentration is 6934 ind $\cdot \mathrm{cm}^{-3}$. Meanwhile, during summer in Lianfengshan, the average concentration is 8563 ind $\cdot \mathrm{cm}^{-3}$. The concentration of air anion varies with the time and place, and the difference is very large.

\subsection{Air Anionic Space Distribution}

\subsubsection{Distribution of Air Anion in the Sea and Forest}

Qing-shan Li [24], a Yanshan University professor, conducted air anion observations in February 2008 to June of the Beidaihe Geziwo Sea, Olympic Avenue, Lianfengshan, 36 Biluota Park Building, Laohushi Sea Park, and Jifa Sightseeing Garden using six monitoring instruments (IC-1000 type and Japan AK103 portable air ion measuring instruments). In the observation, the average value of the negative air ion concentration of Beidaihe was 2000 ind $\cdot \mathrm{cm}^{-3}$, the maximum value was 14,000 ind $\cdot \mathrm{cm}^{-3}$, and the minimum value was $160 \mathrm{ind} \cdot \mathrm{cm}^{-3}$. Figure 7 and Figure 8 are the monthly average line charts of Jinshanzui and Lianfengshan's 


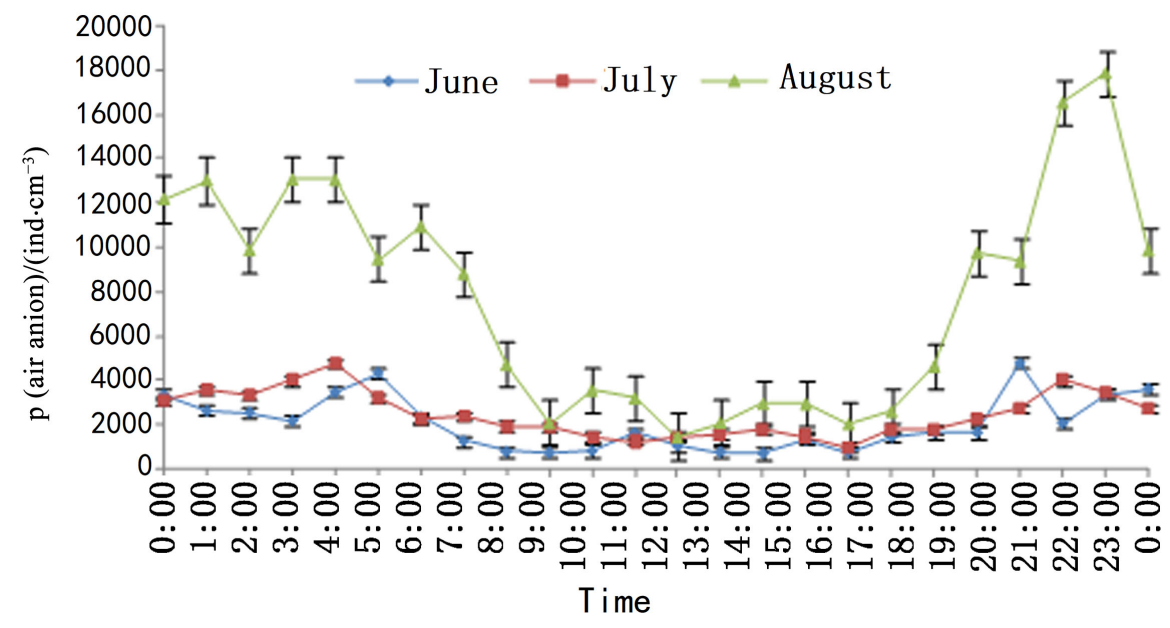

Figure 6. Line chart on the daily variation of anion mass concentration in 24 hours during hot season.

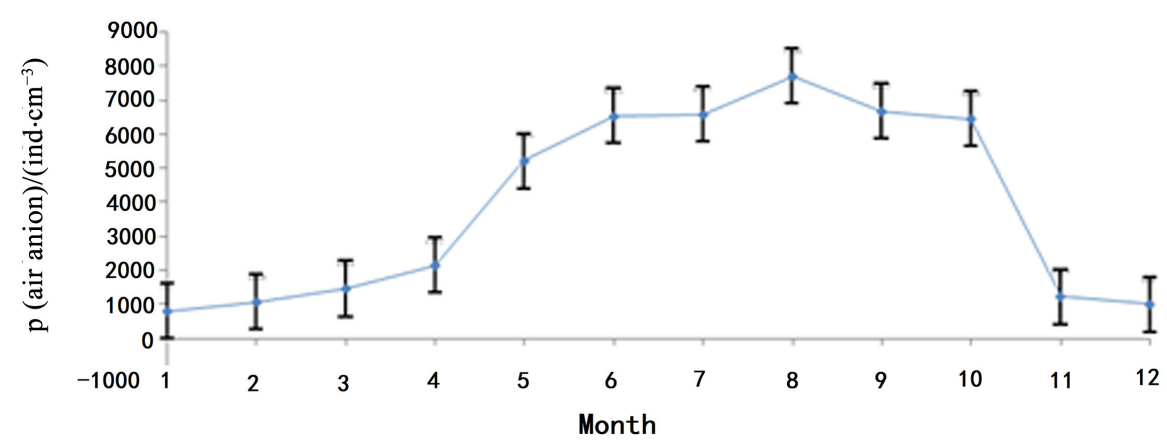

Figure 7. Variation of monthly average mass concentration of air anion in Jinshanzui.

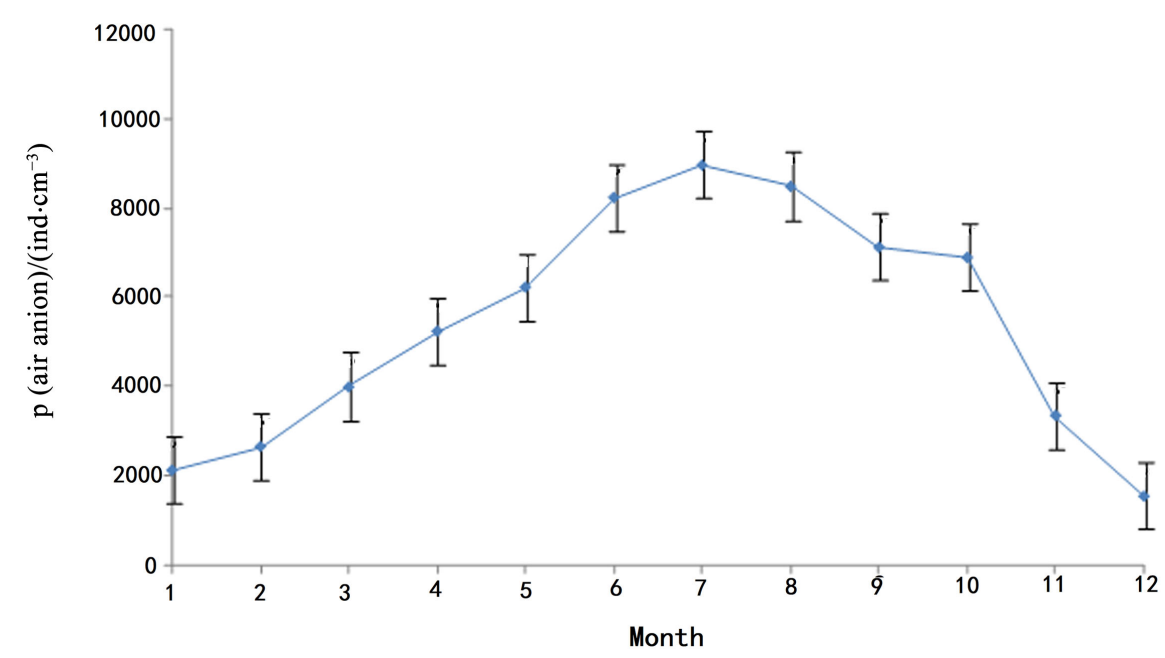

Figure 8. Variation of monthly average mass concentration of air anion in Lianfengshan.

negative air ion concentrations, which are 3902 ind $\cdot \mathrm{cm}^{-3}$ and 5403 ind $\cdot \mathrm{cm}^{-3}$, respectively. The average monitoring approximation of Professor Li Qingshan ( 3550 ind $\cdot \mathrm{cm}^{-3}$ ) and Lianfengshan (4800 ind $\cdot \mathrm{cm}^{-3}$ ) in the Biluota Park is close to the mean, which can be controlled and verified. 
The average monthly negative ion concentration of Jinshanzui air is 7700 ind $\cdot \mathrm{cm}^{-3}$, and the lowest value is 797 ind $\cdot \mathrm{cm}^{-3}$ in January. The average monthly maximum air anion concentration for Lianfengshan was in July at 8965 ind $\cdot \mathrm{cm}^{-3}$, and the average monthly minimum was $1538 \mathrm{ind} \cdot \mathrm{cm}^{-3}$ in December. The average maximum and minimum time is different in two locations, and both locations have a direct relationship between the contribution of negative air ion source. Jinshanzui is located in the seaside, where broken negative air ions in the waves of the sea water molecules release free electrons and become part of the plant's biological discharge. Lianfengshan is located in a tall coniferous forest (mainly composed of oil, black, and masson pines), in which a significant amount of negative charge is generated by the biological discharge of small shrubs. In 2005, Meng [25] reported that trees release negative charge, and rich layers of negative air ions are more abundant in plants. In 2015, Feng [26] conducted a statistical analysis that proved the effect of human activities on negative air ion concentrations and the negative correlation of concentration with traffic. The forest is the least habitable area. Therefore, the negative air ions of the couplet peak mountain area concentration is larger than that of the sea due to the different locations and releases of free electrons caused by the Jinshanzui extremum and the negative air ion concentrations of Lianfengshan in different time periods. According to Shi [27], determined forest recreation areas, such as the research evaluation standard of negative air ion concentrations, are greater than 3000 to 1 and $2000-3000$ for level 2. In the Lianfengshan area, a total of nine months of negative air ion concentration are in class 1 in $3-11$ months a year and only 12 months at level 2 .

\subsubsection{Distribution of Air Anions in the "Early, Middle, and Late" Periods during Summer}

Summer seaside leisure travel usually includes watching the sunrise, afternoon sea bath, dinner after the cool summer, and other recreational programs. Table 1 shows the average air anion concentrations in the morning, noon, and evening during peak travel season (July, August, and September). In the meteorological observation station, the air anion concentrations in June, July, and August are 3435 ind $\cdot \mathrm{cm}^{-3}, 3426$ ind $\cdot \mathrm{cm}^{-3}$, and 11200 ind $\cdot \mathrm{cm}^{-3}$, respectively. In June, the concentration from 13:00 to $15: 00$ is 861 ind $\cdot \mathrm{cm}^{-3}, 1646$ ind $\cdot \mathrm{cm}^{-3}$ in July, and 2212 ind $\cdot \mathrm{cm}^{-3}$ in August. From 19:00 to 21:00, the concentration in June is 2729

Table 1. Anion mass concentration of the three locations in the morning, at noon, and in the evening during the hot season.

\begin{tabular}{cccccccccc}
\hline \multicolumn{3}{c}{ Meteorological observatory } & \multicolumn{3}{c}{ Jinshanzui } & \multicolumn{3}{c}{ Lianfengshan } \\
\hline & $05-07$ & $13-15$ & $19-21$ & $05-07$ & $13-15$ & $19-21$ & $05-07$ & $13-15$ & $19-21$ \\
June & 3435 & 861 & 2729 & 7340 & 4925 & 6833 & 9413 & 6891 & 8214 \\
July & 3426 & 1646 & 2266 & 7366 & 4279 & 7164 & 10123 & 7055 & 8830 \\
August & 11200 & 2212 & 7969 & 8562 & 5946 & 7711 & 9937 & 6903 & 8221 \\
\hline
\end{tabular}


ind $\cdot \mathrm{cm}^{-3}, 2266$ ind $\cdot \mathrm{cm}^{-3}$ in July, and 7969 ind $\cdot \mathrm{cm}^{-3}$ in August. The air anion concentrations follow the order morning > evening $>$ noon.

In Jinshanzui and Lianfengshan, the distribution rule of negative air ion concentrations and the meteorological observation situation are roughly similar, except that the Lianfengshan negative air ion concentrations in July are significantly higher than those in June and August.

\subsection{Relationship between Air Anion and Climatic Conditions}

Air anion is closely related to the ecological environment (vegetation condition and water environment), and the ecological environment is restricted by climatic conditions. The influence of climatic conditions on air anion is analyzed as follows.

\subsubsection{Relationship between Negative Air Ions and Meteorological Elements}

Table 2 for 2009 to 2015 calendar year shows the average of negative air ion concentrations, annual average temperature, annual rainfall days, annual rainfall, annual thunderstorm, annual sunshine hours, and the correlation with the annual average relative humidity. The correlation coefficients of the negative air ion concentrations and main meteorological elements can be obtained through the data analysis of the table. The results of the correlation calculation show that the air anionic concentration is negatively correlated with the annual mean temperature at a correlation coefficient of -0.861 . The number of rainy days is positively correlated at a correlation coefficient of 0.576 . The total annual rainfall is positively correlated at a correlation coefficient of 0.730 . The annual thunderstorms are positively correlated at a correlation coefficient of 0.672 , which is negatively correlated with the annual sunshine time at a correlation coefficient of -0.803 . Relative humidity is positively correlated with the annual average at a correlation coefficient of 0.246 . The correlation coefficients show that the annual precipitation days, annual rainfall, annual thunderstorm days, and the increase in annual average relative humidity for generated negative air ions; a high annual average temperature and sunshine hours contribute to the conduciveness to negative air ions. This study investigates the correlation coefficient and reveals that only annual rainfall can be tested by significance. The correlation between

Table 2. Correlation between the annual average mass concentration of air anion and the main meteorological elements.

\begin{tabular}{ccccccc}
\hline $\begin{array}{c}\text { Annual average } \\
\text { mass } \\
\begin{array}{c}\text { concentration of } \\
\text { anion with- }\end{array}\end{array}$ & $\begin{array}{c}\text { Annual } \\
\text { average } \\
\text { temperature }\end{array}$ & $\begin{array}{c}\text { Annual } \\
\text { rainfall days }\end{array}$ & $\begin{array}{c}\text { Annual } \\
\text { precipitation }\end{array}$ & $\begin{array}{c}\text { Annual } \\
\text { lightning } \\
\text { days }\end{array}$ & $\begin{array}{c}\text { Annual } \\
\text { hours of } \\
\text { sunshine }\end{array}$ & $\begin{array}{c}\text { Annual } \\
\text { average } \\
\text { relative } \\
\text { humidity }\end{array}$ \\
\hline $\mathrm{R}$ & -0.861 & 0.576 & 0.730 & 0.672 & -0.803 & 0.246 \\
Significance test No correlation & $\begin{array}{c}\text { No } \\
\text { correlation }\end{array}$ & 0.031 & $\begin{array}{c}\text { No } \\
\text { correlation }\end{array}$ & 0.058 & 0.049 \\
\hline
\end{tabular}


other meteorological factors and the annual mean of negative air ions is insignificant. Only seven years of data are employed because the concentration of negative air ions average overall less sample data, so can't response air anion overall average data from the real relationship between the overall climate data. If the observation data chain of the negative air ion is long, then the correlation can be changed, and the data of negative air ions will be continuously observed for a long time.

\subsubsection{Relationship between Atmospheric Discharge (Lightning) and Air Anion Concentration}

Figure 9 shows the relationship diagram of the lightning frequency recorded by the lightning locator and the concentration of air anion during a thunderstorm. The horizontal coordinate represents the number of lightnings. The vertical coordinate of the left side is the air anion concentration, and the vertical coordinate of the right side is the lightning frequency. The six sets of lightning bolts were selected from the 123 lightning processes from 2009 to 2015, and the corresponding air anion concentration data were calculated according to the lightning sequence. The data of the six sets of lightnings were as follows: 53 , $117,509,1033,1505$, and 1980; meanwhile, the corresponding air anion concentrations were $2020,2486,4311,11,236,37,451$, and 45,570 ind $\cdot \mathrm{cm}^{-3}$, respectively. Figure 9 shows the lightning number more than 1000 times, where in the concentration of negative air ions is 11,000 ind $\cdot \mathrm{cm}^{-3}$ above, more than 1500 times the air anion concentrations reach above 35,000 ind $\cdot \mathrm{cm}^{-3}$, and concentration reaches more than 2000 times than 45,000 ind $\cdot \mathrm{cm}^{-3}$ above. The atmospheric discharge of a thunderstorm can have a considerable amount of negative air ions with an extremely small particle size (statistics show that when the migration rate of thunder and lightning is 0.4 or more at a negative air ion concentration of 1.0 or higher, the concentration of negative air ion is more than twice as many). This condition can be attributed to thunder generally occurring in the cumulus cloud

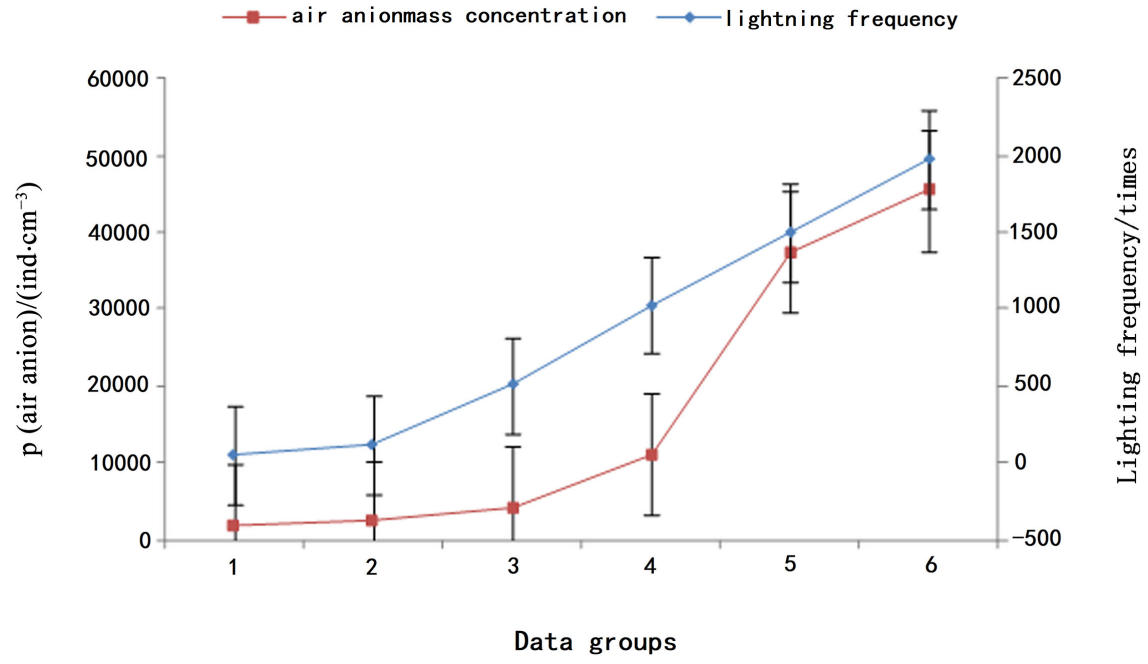

Figure 9. Line chart on the relationship between the lightnin. 
(cumulonimbus), in which a considerable amount of negative charges exist. The top has numerous positive charges, while the cumulonimbus has unstable structures and a strong turbulence. The temperature in the cloud layer is extremely low, and with the positive and negative charges on the airflow movement, intense collision produces a huge current in the form of lightning. The lightning current supercooled water droplets are caused by strong ionization, thereby producing a considerable amount of electronic that adheres to the water surface and falls to the ground with precipitation and forming the air in a thunderstorm or the presence of large amounts of negative air ions after the thunderstorm.

\subsection{Relationship between Air Anions and Atmospheric Pollutants}

\subsubsection{Relationship between Air Anions and the Months of the Inhalable Granules}

Figure 4 shows a line chart of the average concentration distribution of sulfur dioxide, nitrogen dioxide, carbon monoxide, and ozone. The contrast curves in Figure 3 and Figure 4 show the visible concentration of negative air ions, high values of sulfur dioxide and nitrogen dioxide, and low carbon monoxide concentration that corresponds to the month and ozone. The month and the concentration of negative air ions are high.

The study of Lin et al. [28] indicates that at 20,000 ind $\cdot \mathrm{cm}^{-3}$, the amount of fly ash in the air will be reduced by more than $98 \%$, which contains a high concentration of negative air ions in the air with small particle sizes, including $1 \mu \mathrm{m}$ of the most harmful dust, bacteria, viruses, and other fine particulate matter. The bacteria, dust, and smoke in the air are positively charged particles that can easily be deposited into neutral particles with small particles of air. In addition, PM2.5 fine particles, including nitric oxide, sulfur, dust, and tiny aerosol particles, such as bacteria and viruses, combined with the Brownian motion of negative air ions in the air and land, largely eliminate PM2.5 [29] the harm of human body.

Although air anions and atmospheric PM2.5 positive ions can be neutralized, negative air ions can be removed from air pollution. In a weak air pollution, the PM2.5 concentration is very low, that is, the ratio of positive and negative ions in the air is less than one. Negative air ions can reduce atmospheric particulate matter pollution and still obtain a very high concentration of negative air ions. Therefore, fresh air can only be obtained when air pollution is effectively controlled and the environment is good. Thus, the ecological environment should be protected.

\subsubsection{Relationship between Air Anion and Major Chemical Pollutants}

The relationship between negative air ions and major chemical pollutants in fine particulate matter is shown in Table 3. The concentration of negative air ions in the atmosphere and the concentrations of pollutants, such as nitrogen dioxide, sulfur dioxide, and carbon monoxide, show a negative correlation with correla- 
tion coefficients $0.555,0.569$, and 0.484 , respectively. In addition, such concentration is positively correlated with the ozone at a correlation coefficient of 0.217 . The significance test result of the correlation of negative air ions and the main atmospheric pollutants in Table 3 is a P-value between 0.01 and 0.05 , which indicates a significant correlation. The samples of negative air ions and pollutants of positive and negative correlations have obvious repeatability; the entire negative air ion concentration data and the main pollutant concentration data are in the reverse phase. The significance test on the samples can reflect the general rule.

\subsection{Small Ions and Small Ion Concentration Differences}

The data of $\mathrm{k}=1.0$ (small ions) and $\mathrm{k}=0.4$ (ion) of negative air ions are compared. The concentrations of the two kinds of mobility differences are shown in Table 4.

In the table, the summer average concentration of the negative air ion with a migration rate of $\mathrm{k}=0.4$ is $6191 \mathrm{ind} \cdot \mathrm{cm}^{-3}$, and the migration rate is 1.5 times that of $\mathrm{k}=1$ concentration (4112 ind $\cdot \mathrm{cm}^{-3}$ ). In fall, the average concentration is 3450 ind $\cdot \mathrm{cm}^{-3}$, which is 1.9 times the migration rate of $\mathrm{k}=1\left(1821 \mathrm{ind} \cdot \mathrm{cm}^{-3}\right)$. The average winter concentration is $490 \mathrm{ind} \cdot \mathrm{cm}^{-3}$, which is 1.3 times that of $\mathrm{k}=$ $1\left(377\right.$ ind $\left.\cdot \mathrm{cm}^{-3}\right)$. The average spring concentration is 908 ind $\mathrm{cm}^{-3}$, which is 1.5 times the value of $\mathrm{k}=1\left(611 \mathrm{ind} \cdot \mathrm{cm}^{-3}\right)$. For many years in the Beidaihe station, the annual average relative humidity has been $69 \%$ (Table 1 ), the air relative humidity has exceeded $69 \%$, and the air negative ion concentrations at $\mathrm{k}=1$ and $\mathrm{k}=0.4$ have been very high (average concentration for $2965 \mathrm{ind} \cdot \mathrm{cm}^{-3}$ and 5662 ind $\cdot \mathrm{cm}^{-3}$ and mobility of $\mathrm{k}=0.4$ with small ion concentration is significantly higher than the mobility of the small ion concentration of $k=1$ ). When the relative humidity is below $69 \%$, the concentration of air anion at $\mathrm{k}=1$ and the migration rate $\mathrm{k}=0.4$ are significantly low, and the concentration difference is insignificant at 497 ind $\cdot \mathrm{cm}^{-3}$ and 687 ind $\cdot \mathrm{cm}^{-3}$, respectively.

\section{Conclusion and Discussion}

\subsection{Conclusion}

The average annual mean of air anion in Beidaihe is 3678 ind $\cdot \mathrm{cm}^{-3}$ (three sites on average), and the summer and autumn concentrations are significantly higher than those in winter and spring. The Beidaihe observatory and Jinshanzui air anion concentrations are the highest in August and the lowest in January. The maximum negative air ion concentration in Lianfengshan is in July and the minimum is in December, the concentration of air anion changes. The daytime concentration is significantly lower than that at nighttime. The average peak appears at night or in the morning, and the lowest value occurs between noon and afternoon.

The comparison of the three stations shows that the presence of more vegetation near the shore leads to high air anion concentration. 
Table 3. Correlation between the mass concentration of anion and the mass concentration of the main pollutants in Beidaihe $(n=72)$.

\begin{tabular}{cccccc}
\hline Anion with- & $\mathrm{NO}_{2}$ & $\mathrm{SO}_{2}$ & $\mathrm{CO}$ & $\mathrm{O}_{3}$ & $\mathrm{PM}_{2.5}$ \\
\hline correlation coefficient & -0.55536 & -0.56898 & -0.48375 & 0.21683 & -0.54429 \\
P-Value & 0.0191 & 0.0189 & 0.0166 & 0.0185 & 0.0189 \\
\hline
\end{tabular}

Table 4. Anion mass concentration on the drift mobility's value $\mathrm{k}=1$ and $\mathrm{k}=0.4$, the monthly average humidity.

\begin{tabular}{cccccccccccccc}
\hline Months & 1 & 2 & 3 & 4 & 5 & 6 & 7 & 8 & 9 & 10 & 11 & 12 \\
\hline $\begin{array}{c}\text { Mass concentration } \\
\text { for drift mobility: } \\
\quad \text { K }=1\end{array}$ & 365 & 371 & 402 & 439 & 992 & 2064 & 2488 & 7786 & 2736 & 2217 & 512 & 396 \\
$\begin{array}{c}\text { Mass concentration } \\
\text { for drift mobility: } \\
\quad \text { K = }\end{array}$ & 474 & 482 & 523 & 615 & 1587 & 3509 & 5722 & 9343 & 5746 & 3990 & 614 & 515 \\
$\begin{array}{c}\text { Monthly average } \\
\text { humidity }\end{array}$ & 55 & 62 & 59 & 62 & 66 & 83 & 87 & 86 & 78 & 71 & 61 & 54 \\
\hline
\end{tabular}

The annual average concentration of air anion is positively correlated with the annual rainfall, total rainfall, thunderstorm days, and average relative humidity. The annual average temperature and sunshine time are negatively correlated. Apart from the significant annual rainfall, the correlation test of the annual mean concentration of air anion is insignificant or unrelated to the annual mean of the other meteorological elements. Thunderstorms significantly contribute to the release of negative air ions.

The air anion and fine particulate matter PM2.5 concentrations are negatively correlated with the concentrations of nitrogen dioxide, sulfur dioxide, and carbon monoxide, but positively correlated with the ozone concentration and is tested by significance. Environmental protection should be strengthened, and the ecological environment should be protected to maintain the high concentration of air and negative ions.

The transfer rate $\mathrm{k}=0.4$ (small ion) of air anion has an annual concentration $\left(2760\right.$ ind $\left.\cdot \mathrm{cm}^{-3}\right)$, that is, 1.6 times the average annual concentration of air anion in $\mathrm{k}=1$ (smaller ion). In summer and autumn, the average annual concentration of air anion is 1.7 times that of $\mathrm{k}=1$ and 1.4 times in winter and spring.

\subsection{Discussion}

Air anion concentration is closely related to environmental conditions, especially the decisive role of ecological environment. The natural ecological environment of the Beidaihe coastal area determines the high concentration of negative air ions and analyzes its influence. This phenomenon can be attributed to several reasons.

Contribution of the ocean. The coastline landscape rendering of the rocks and sand (granite sand) structure, its summer prevailing southwest, northeast coast 
to roughly the southwest, the wind blowing from the front to the shore, and waves directly impact the coast, sand, and rock surface. Moreover, break after splashing sea spray is formed in many free electrons such that water droplets fly into the electrons, along with the oxygen in the air, that is, the air anion. The sea breeze produced by the sea and land difference, as well as the negative air ion generation, are also very advantageous. In winter, the dominant wind direction is the north wind, the wind and waves are "offshore," and the long winter seasonal coastline is basically covered by sea ice, which is not conducive to air anion production.

Population. Beidaihe has an area of $70.14 \mathrm{~km}^{2}$. The green coverage rate of Beidaihe city is $59.22 \%$, the unbuilt city green coverage rate is $73.64 \%$, and the per capita public green space is $54.49 \mathrm{~m}^{2}$. The total population is 85,729 (2011 census results at the end of October), and the urban population density of 1221 people per $\mathrm{km}^{2}$ is significantly lower than the urban population densities of other cities. The population and urban metabolites, such as waste water, waste gas, and waste, as well as smokeless industries, are more conducive to air anion generation.

Ecological environment. Zigzag curved coastline, large tidal flats, rolling hilly terrain, diverse vegetation, and the sea breeze climate play key roles in the concentration of negative air ions.

Comprehensive impact. The waves hit the rocks or the shore, thereby causing the water molecules to break and release free electrons.

Tall coniferous forest biological discharge. Air ionization is catalyzed by plant secretions. Photosynthesis releases oxygen. The water vapor in the wetland increases the comprehensive role of moist air and strengthens the negative air ion release. Climate, oceans, vegetation, and undulating terrain, such as the background, determine the inter-annual characteristics of negative air ion concentrations and mean monthly change rule, including climate and plant growth, as well as the fall negative air ion concentration, which is significantly greater than that of winter.

\section{Acknowledgements}

This work was supported by the National Natural Science Foundation of China (Nos. 41375121 and 41305079).

\section{References}

[1] Dal Maso, M., Kulmala, M. and Riipinen, I., et al. (2005) Formation and Growth of Fresh Atmospheric Aerosols: Eight Years of Aerosol Size Distribution Data from SMEAR II ,HyytiäIä, Finland. Boreal Environment Research, 10, 323-336.

[2] Shao, H.R., He, Q.C. and Yan, H.P., et al. (2005) The Study on the Spatial and Temporal Characteristics of Air Anion Concentration in Beijing. Journal of Beijing Forestry University: Natural Science Edition, 27, 35-39.

[3] He, X.P. and Li, A.B. (1999) The Effects of Air Ions on the Enzymes of Living Organisms. Foreign Medical Geographic Book, 12, 57-60. 
[4] Sirota, T.V., Safronova, V.G. and Amelina, A.G., et al. (2008) The Effete of Negative Air Ions on the Respiratory Organs and Blood. Biophysics, 53, 457-462. https://doi.org/10.1134/S0006350908050242

[5] Liu, Y., Li, A.B. and Lei, Y.M. (1999) The Biological Effect of Air Anion. Foreign Medical Geographic Book, 12, 55-57.

[6] Shalnov, G.A. (1994) Air Ionization and Its Effects on the Immune System of Man. Bioradiocal, 34, 391-397.

[7] Li, F., Lan, Z.M. and Hu, T.L., et al. (1999) The Concentration of Outdoor Air Ions in the Sanatorium of Emei Mountain Area. China Physiotherapy Journal, 1, 22-23.

[8] Zhou, Z.Y., Kuang, X.Y. and Shen, R.J. (1996) The Analysis of Air Anionic Observation in Hangzhou Landscape Sanatorium. Chinese Recuperation Medicine, 5, 9-10.

[9] Huang, J.W. and Tao, J.Y. (2002) Air Negative Ion Resource Development and Ecotourism. Journal of Central China Normal University (Natural Science Edition), 36, 253-257.

[10] Wei, C.L., Wang, J.T. and Jiang, Y.L., et al. (2006) The Distribution Characteristics of Air Anion Concentration in Different Ecological Functional Zones of Hefei City and Its Relationship with Meteorological Factors. Journal of Applied Ecology, 17, 2158-2162.

[11] Huang, Y.L., Chen, D.H., Lu, D., et al. (2004) Air Anion and Urban Environment. Drought Environment Monitoring, 18, 208-211.

[12] Chen, C.Z., Gan, D.X. and Chen, X.Y. (2009) Effects of Different Ecological Environment Conditions on the Concentration of Air Anion. Modern Agricultural Science, 16, 174-176.

[13] Shao, H.R., Du, J.J., Shan, H.C., et al. (2005) A Preliminary Assessment of Air Cleanliness in Beijing by Air Anion Concentration. Journal of Beijing Forestry University, 27, 56-59.

[14] Liang, S., Tong, Q.X. and Chi, M.J. (2010) Effects of Urban Vegetation on Air Negative Ions. Subtropical Plant Science, 39, 46-50.

[15] Bai, B.X., Chen, D.H., Xu, T.T., et al. (2014) Analysis on the Change of Air Anion Concentration in Different Vegetation Areas in Central and Northern Henan. Journal of Ecological Environment, 25, 1629-1637.

[16] Hu, X.S., Liu, D.X., Hong, W., et al. (2012) The Effects of Different Types of Green Space Air Anion Effect in Fuzhou. Journal of Agronomy, 2, 42-45.

[17] Chang, A., Liu, M. and Li, C.L. (2015) The Relationship between Air Negative Ion Concentration and Meteorological Conditions. Beijing Agriculture, 2, 116-117.

[18] Ren, X.X., Chen, Q.J., Dong, J.H., et al. (2016) The Characteristics of Air Anion in Hangzhou City and Its Relationship with Meteorological Factors. Environmental Protection Science, 42, 109-112.

[19] Wang, F., Li, B. and Zhou, H.W. (2014) The Correlation between Air Anion Concentration and Meteorological Factors in Urban Forest Park. Journal of Northeast Forestry University, 44, 18-21.

[20] Wang, W. and Chen, M. (2016) Urban Green Space Air Anion and PM2.5 Concentration Distribution Characteristics and Its Relationship with Microclimate-Taking Hefei Swan Lake as an Example. Ecological Environment Journal, 25, 1499-1507.

[21] Zhao, Y.P. (2014) Study on the Distribution of Negative Ion Distribution of Envi- 
ronmental Air in Shanghai and Its Correlation with Influencing Factors. Shanghai Normal University, Shanghai, 1-74.

[22] Yan, X.Q. (2010) The Spatial Distribution of Negative Ions of Forest and Wetland in Qingdao. Forestry Science, 46, 66-69.

[23] Cong, Q. and Sun, L.J. (2010) The Establishment of the Distribution of Negative Oxygen Ion Concentration in Dalian and the Establishment of Prediction Model. Journal of Meteorology and Environment, 26, 44-47.

[24] Li, Q.S., Liu, J., Di, Y.B., et al. (2008) The Determination of Air Anion Concentration in Beidaihe and the Standard of Negative Ion Evaluation. Journal of China Environmental Management Cadre Institute, 18, 1-4.

[25] Meng, J.J. and Zhang, Y. (2005) Air Anion on the Ground Is Mainly Derived from the Tip Discharge of Plants. Environmental Science and Technology, 28, 112-113.

[26] Feng, P.F., Yu, X.W. and Zhang, X. (2015) The Concentration of Air Anion Concentration and Its Influence Factors in Different Vegetation Types in Beijing. Journal of Ecological Environment, 24, 818-824.

[27] Shi, Q., Shu, H.F., Zhong, L.S., et al. (2004) Research on Air Anion Evaluation in Forest Recreation Area. Forestry Science, 40, 36-40.

[28] Lin, J.M., Song, G.Q. and Zhao, L.X. (2006) Environment, Health and Negative Oxygen Ion. Chemical Industry Press, Beijing, 1-300.

[29] Tan, Y.J., Wang, E., Zhang, P.Y., et al. (2013) Research Progress of Air Anion Spatiotemporal Changes and Health Care Function. Northern Horticulture, 37, 208-211. 